\title{
Hemorragia digestiva en paciente con cáncer de orofaringe. A propósito de un caso
}

\author{
Digestive haemorrhage in a patient with oropharyngeal cancer. \\ A case study
}

\author{
M. Rico ${ }^{1}$, F. Arias de la Vega ${ }^{1}$, M.T. Vila ${ }^{1}$, V. Chicata ${ }^{1}$, G. Asín ${ }^{1}$, M.L. Gómez Dorronsoro'
}

\section{RESUMEN}

Las metástasis gástricas de tumores sólidos son muy infrecuentes y en la mayoría de los casos aparecen simultáneamente con otras metástasis. Los tumores primarios que más frecuentemente metastatizan a este nivel son los de pulmón y mama. Los síntomas y datos clínicos que presentan son inespecíficos y pueden abarcar desde la dispepsia hasta una hemorragia gastrointestinal masiva. Para el diagnóstico la gastroscopia es la herramienta fundamental. En esta nota clínica presentamos un caso inusual de hemorragia digestiva masiva en un paciente con un carcinoma de orofaringe.

Palabras clave. Hemorragia digestiva. Carcinoma de orofaringe.

\begin{abstract}
Gastric metastases from solid tumours are very infrequent and in most cases appear simultaneously with other metastases. The most frequent primary tumors are lung and breast. Clinical data and symptoms are non-specific, and can range from abdominal discomfort to massive gastrointestinal bleeding. The diagnoses must be established by gastroscopy and biopsy. We present an unusual case of digestive haemorrhage secondary to gastric metastases from oropharyngeal carcinoma.
\end{abstract}

Key words. Digestive haemorrhage. Oropharyngeal carcinoma.
1. Servicio de Oncología Radioterápica. Hospital de Navarra. Pamplona.

2. Servicio de Anatomía Patológica. Hospital de Navarra. Pamplona.

Recepción: 4 de mayo de 2009

Aceptación provisional: 29 de mayo de 2009

Aceptación definitiva: 23 de julio de 2009

\section{Correspondencia}

Mikel Rico Osés

Servicio de Oncología Radioterápica

Hospital de Navarra

Irunlarrea, 3

31008 Pamplona

Tfno. 649464695

E-mail: lekimrico@hotmail.com 


\section{INTRODUCCIÓN}

Las metástasis gástricas de tumores de cabeza y cuello son muy infrecuentes. A pesar de ello, y ante el aumento de la supervivencia de los pacientes con estos tumores, debamos descartar la presencia de metástasis en el tracto digestivo cuando haya datos clínicos que las sugieran. El caso que presentamos muestra cómo en un paciente diagnosticado de carcinoma de orofaringe se produjo progresión a nivel gástrico tras haberse logrado una respuesta completa de su enfermedad. Se analiza en este trabajo cuáles son los tumores metastáticos que más frecuentemente asientan a nivel gástrico, cómo se presentan dichas metástasis y cuáles son las técnicas diagnósticas y terapéuticas con las que contamos hoy en día.

\section{CASO CLÍNICO}

Varón de 55 años derivado a nuestro hospital en noviembre de 2005 por odinofagia y sangrado oral. En la exploración física se objetivó una úlcera de aspecto necrótico de $4-5 \mathrm{~cm}$ de diámetro en pilar amigdalino y amígdala izquierda que se biopsió, con resultado de carcinoma epidermoide. En el TAC se observaron adenopatías laterocervicales ipsilaterales tanto submaxilares como yugulodigástricas. La analítica sanguínea y el resto de exploraciones fueron normales. Así se estableció el diagnóstico de carcinoma epidermoide localmente avanzado de orofaringe (T3-N2b-M0, Estadio IVa) e inició tratamiento quimiorradioterápico. El tratamiento consistió en radioterapia hiperfraccionada (120 cGy por fracción, 2 fracciones/día, hasta $7.680 \mathrm{cGy}$ ), y cisplatino, $20 \mathrm{mg} / \mathrm{m} 2 /$ día en perfusión continua durante 120 horas, entre los días 1 a 5 y 21 a 25 de tratamiento. Al final del tratamiento tanto la exploración física como el TAC mostraban respuesta completa.

El paciente se mantuvo asintomático hasta marzo de 2007 cuando acudió a nuestro hospital por un cuadro de astenia, inestabilidad y dolor abdominal seguido de hematemesis masiva con afectación clínica y hematológica ( $\mathrm{Hb} 7,1 \mathrm{~g}$, hematocrito 21,5\%). La gastroscopia (Fig. 1) mostraba una tumoración ulcerada en el esófago distal, sobre cardias extendiéndose a curvatura mayor y cara anterior y posterior de estómago. El resultado de la biopsia (Fig. 2) fue de carcinoma epidermoide compatible con metástasis de carcinoma de laringe.
A lo largo del ingresó fueron necesarias varias transfusiones y se inició tratamiento con somatostatina pese a lo que el sangrado se mantuvo activo. Se inició entonces tratamiento radioterápico de carácter paliativo con intención hemostática administrándose 20Gy en 5 fracciones de $400 \mathrm{cGy}$ con buena tolerancia digestiva y consiguiendo la remisión de los episodios de sangrado. El paciente fue dado de alta quedando asintomático durante otros 5 meses tras los que falleció por diseminación metastásica.

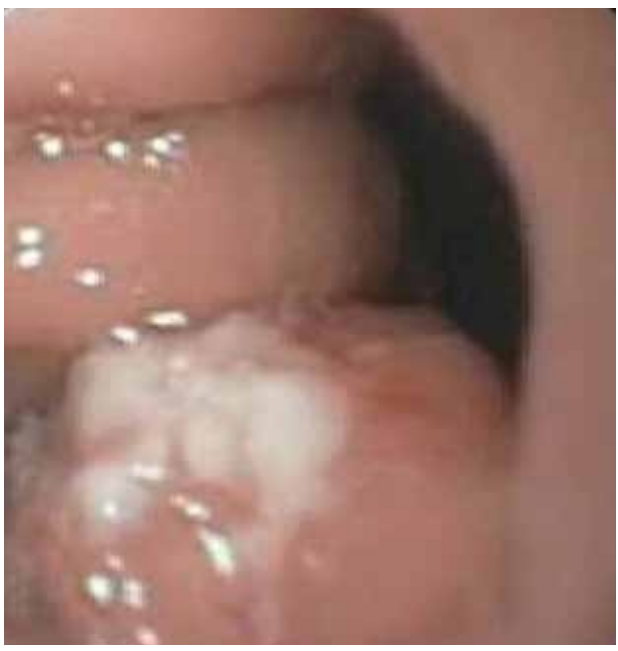

Figura 1. Gastroscopia mostrando tumoración excrecente en esófago distal sobre cardias.

\section{DISCUSIÓN}

Las metástasis en estómago son infrecuentes apareciendo distintos datos en las diferentes series de autopsias ${ }^{1}$. Encontramos desde el 0,7\% de metástasis gástricas en 67 casos de Green ${ }^{2}$, hasta $347(5,4 \%)$ de 6.380 casos de las autopsias de pacientes con tumores sólidos de $\mathrm{Oda}^{3}$. Otras series encontraron metástasis en $1,7 \%$ de 1.010 autopsias (Menuck) ${ }^{4}$. El tumor primario se localiza con mayor frecuencia en pulmón, mama, esófago y piel (melanoma), correspondiendo al tumor primario de cabeza y cuello el $6,2 \%$ de las metástasis gástricas $^{5,6}$. 


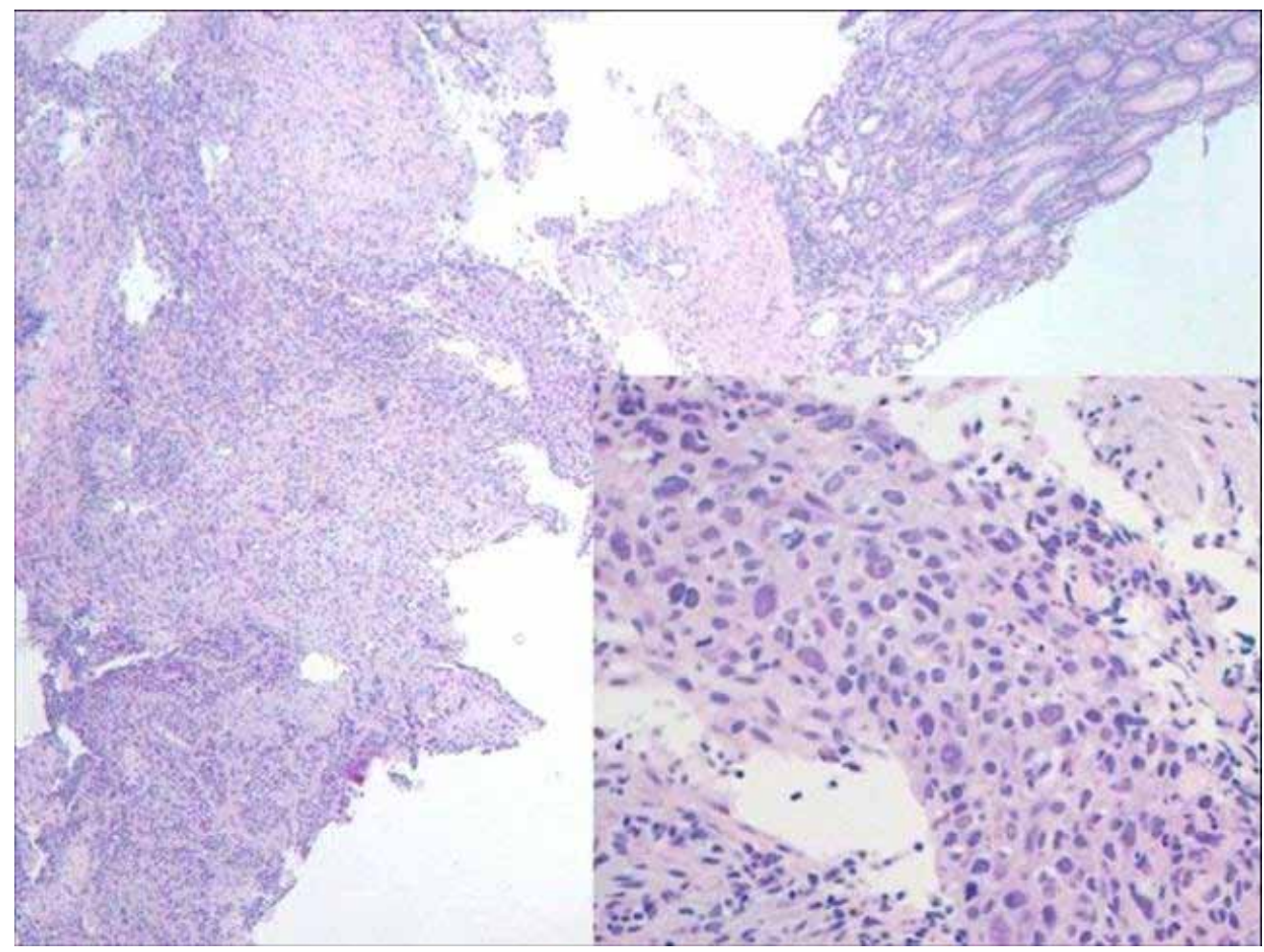

Figura 2. Biopsia gástrica con metástasis de carcinoma escamoso. Detalle de carcinoma escamoso. HE x 200.

Por otra parte, en la autopsia de 587 pacientes con tumores de cabeza y cuello se encontraron metástasis en estómago en 15 ocasiones $(2,6 \%)^{3}$ y es que las metástasis a instancia de los tumores de cabeza y cuello han ido también aumentando conforme ha mejorado la supervivencia de dichos pacientes, llegando a producirse metástasis clínicamente aparentes entre el $10 \%$ y el $15 \%$ de los $\operatorname{casos}^{7,8}$ y alcanzando el $57 \%$ si se realizan análisis histológicos ${ }^{9}$.

Como en el caso que nos ocupa, la mayoría de los pacientes que posteriormente desarrollaron metástasis tuvieron una respuesta completa de su enfermedad tras el tratamiento inicial, de hecho el control locorregional del carcinoma de cabeza y cuello a los 5 años asciende al $84 \%$ tras radioterapia definitiva ${ }^{8}$. En cerca de la mitad de los pacientes la recaída se produjo en el lugar del primer tumor, pero en hasta un $44,2 \%$ de los casos la recaída se producía como enfermedad a distancia sin recurrencia locorregional ${ }^{7}$.

Se ha establecido en diversos estudios una relación significativa entre la aparición de metástasis a distancia y los estadios IV, la afectación cervical ganglionar (N) y el T tumoral del carcinoma escamoso de cabeza y cuello, siendo el $\mathrm{N}$ el más importante de estos factores ${ }^{7,8,10,11}$. El control locorregional, el sexo y el nivel ganglionar también se mostraron como factores relacionados con las metástasis a distancia para Majid $\mathrm{O}^{8}$.

La mayoría de las metástasis de los tumores de cabeza y cuello se dan en los 2 primeros años tras el diagnóstico, apareciendo la mitad de ellas entre los 10 y los 12 primeros meses ${ }^{7,8}$. Más de la mitad de las metástasis en estómago (sin tener en cuenta su origen) suelen aparecer dentro del primer año desde el diagnóstico del tumor primario $^{3,6}$. En nuestro caso se produjeron a los 15 meses. 
Los signos y síntomas clínicos de las metástasis gástricas son inespecíficos y aparecen tardíamente, y consisten en sangrado digestivo, -que se presenta bien como anemia ferropénica o como sangrado agudo- dispepsia, náuseas y vómitos, dolor abdominal, o pérdida de peso ${ }^{1-4,6}$.

Desde el punto de vista endoscópico las lesiones son predominantemente solitarias, afectan a los tercios medio y superior del estómago y se localizan en la curvatura mayor $^{3,6}$. Se encuentran distintas apariencias endoscópicas: pueden asemejarse a un tumor submucoso sin o con depresión central (que correspondería al signo radiográfico del ojo de toro) o a cáncer gástrico primario (como tumor polipoideo, ulcerativo o infiltrante difuso). La biopsia endoscópica confirma el diagnóstico en el $90 \%$ de los casos ${ }^{3}$.

La supervivencia de los pacientes con cáncer de cabeza y cuello que presenta metástasis se reduce de forma dramática. La mediana de supervivencia es de 4,3 meses y el $86,7 \%$ no supera el año de vida ${ }^{7}$. Por su parte, el $50 \%$ de los pacientes que presentan metástasis gástricas fallecen a los 4,75 meses aunque se conocen casos de supervivencia mayor de 2 años $^{12}$. En el caso de nuestro paciente, el fallecimiento se produjo a los 4,5 meses.

A pesar del mal pronóstico relacionado tanto con las metástasis provenientes de tumores de cabeza y cuello como de las metástasis que asientan sobre el estómago es posible y obligado paliar la sintomatología de la que se acompañan. La cirugía en casos de sangrado ${ }^{12}$ es una de las posibilidades, aunque la probable existencia de otros puntos de diseminación y la morbilidad asociada a la intervención pueden suponer obstáculos insalvables para esta. Las técnicas endoscópicas como escleroterapia, fotocoagulación o coagulación con argón también pueden ser efectivas en pacientes con lesiones accesibles. La radioterapia es también una técnica útil en el control del sangrado aunque no modifique el pronóstico ${ }^{13}$.

A pesar de lo relativamente infrecuente de las metástasis gástricas en el cáncer de orofaringe, conviene tener presente su posible existencia, en especial en aquellos pacientes con afectación ganglionar y que presenten clínica compatible, debiéndose realizar estudio endoscópico dada su alta rentabilidad diagnóstica. La radioterapia se perfila como una buena alternativa paliativa para el control local de los síntomas.

\section{BIBLIOGRAFÍA}

1. C.C. Hsu. Endoscopic features of metastatic tumors in the upper gastrointestinal tract. Endoscopy 1996; 28: 249-253.

2. LiNDA K, GREEN MD. Hematogenous metastases to the stomach. Cancer 1990; 65: 15961600 .

3. OdA I, Kondo H. Metastatic tumors to the stomach: analysis of 54 patients diagnosed at endoscopy and 347 autopsy cases. Endoscopy $2001 ; 33: 507-510$.

4. Menuck LS, Amberg JR. Metastatic disease involving the stomach. Am J Dig Dis 1975; 20: 903-913.

5. Telerman A. Gastrointestinal metastases from extra-abdominal tumors. Endoscopy 1985; 17; 99-101.

6. De Palma GD. Metastatic tumors to the stomach: clinical and endoscopic features. World J Gastroenterol 2006; 12: 7326-7328.

7. Calhoun K. Distant metastases from head and neck squamous cell carcinoma. Laryngoscope 1994; 104: 1199-1205.

8. MAJID O. Distant metastases after definitive radiotherapy for squamous cell carcinoma of the head and neck. Head Neck 2003; 25: 629-633.

9. Gowen GF, DeSuto-Nagy, G. The incidence and sites of distant metastases in head and neck carcinoma. SGO 1963; 47: 603-607.

10. LAHOZ ZAMARRO MT. Metástasis a distancia en pacientes con carcinoma de laringe avanzado. Acta Otorrinolaringol Esp 2001; 52: 307311.

11. Arias F, Villafranca E, Dueñas MT, Vera R. Factores pronósticos en el carcinoma de cabeza y cuello. An Sist Sanit Navar 2000; 24 (Supl 1): 73-81.

12. Ming-Hsun Wu. Clinicopathological study of gastric metastases. World J Surg 2007; 31: 132-136.

13. TAAL BG. Clinical and endoscopic features of melanoma metastases in the upper GI tract. Gastrointest Endosc 1999; 50: 261-263. 